\title{
AMOR PELA HONRA, EMULAÇÃO, E A PSICOLOGIA DOS VÍCIOS DIABÓLICOS ${ }^{1}$
}

\author{
Houston Smit \\ Mark Timmons ${ }^{2}$ \\ University of Arizon
}

"O amor pela honra é o companheiro constante da virtude."

ApH 7:257

\begin{abstract}
RESUMO: Nos últimos anos, muito foi escrito a respeito das virtudes e das virtudes particulares expostas na ética de Kant, concentrando-se em particular no Tugendlehre, parte II da Metafísica da Moral (ver, por exemplo, Betzler 2008). Menos atenção foi dada ao que Kant tem a dizer sobre os vícios e sobre os vícios particulares. A própria discussão de Kant a respeito dos vícios escolhidos no Tugendlebre é bastante breve, pontuada por observações a respeito das fontes psicológicas de traços de caráter viciosos. Em contraste, o que encontramos em algumas das anotações de aula, é uma discussão consideravelmente rica sobre a psicologia de outros vícios relacionados envolvendo aquilo a que Kant se refere como emulação - um "impulso" implantado na natureza humana que inclina fortemente os homens a serem "iguais aos outros em cada aspecto" (V 27:695). Embora este impulso implantado tenha o bem do auto-melhoramento como seu propósito, sob algumas circunstâncias ele contribui para os vícios diabólicos da inveja, da ingratidão e da Schadenfreude. Nosso objetivo básico aqui é fornecer uma interpretação das ideias de Kant a respeito da psicologia dos vícios diabólicos - como indivíduos sucumbem a estes vícios - baseados em observações das Lectures. É de particular interesse em que medida estes vícios compartilham de uma unidade psicológica subjacente, uma afirmação sugerida por algumas das observações de Kant.
\end{abstract}

\begin{abstract}
Much has been written in recent years about virtue and the particular virtues featured in Kant's ethics, focusing in particular on the Tugendlehre, part II of The Metaphysics of Morals (see, for example, Betzler 2008). Less attention has been given to what Kant has to say

1 Tradução do original em inglês realizada por Luisa Caroline da Silva Pogozelski (Mestranda do Programa de Pós-Graduação em Filosofia da Universidade Federal de Pelotas).

2 Este é um trabalho inteiramente colaborativo; a ordem de autoria é alfabética. Este estudo foi publicado pela primeira vez em inglês em Kant's Lectures on Ethics: A Critical Guide, L. Denis e O. Sensen (ed.), Cambridge: Cambridge University Press, 2015, e foi apresentado no segundo Workshop on Naturalism: Methodological Challenges, da Universidade Federal de Pelotas, Brasil, de 2 a 5 de Dezembro de 2014. Gostaríamos de agradecer ao público do workshop pelos comentários proveitosos.
\end{abstract}




\section{Dossiê Naturalismo, Dissertatio - Volume Suplementar 02 | UFPel [2015]}

about vice and the particular vices. Kant's own discussion of select vices in the Tugendlehre is quite brief, punctuated with remarks about the psychological sources of vicious character traits. In contrast, what we find in some of the lecture notes, is a fairly rich discussion of the psychology of other-regarding vices involving what Kant refers to as emulation - an "impulse" implanted in human nature that strongly inclines humans to be "equal to the other in every respect" (V 27:695). Although this implanted impulse has the good of self-improvement as its purpose, under certain circumstances it contributes to the devilish vices of envy, ingratitude, and Schadenfreude. Our primary aim here is to provide an interpretation of Kant's views concerning the psychology of the devilish vices - how individuals succumb to these vices - based on remarks in the Lectures. Of particular interest is the extent to which these vices share an underlying psychological unity, a claim suggested by some of Kant's remarks. Before turning to the psychology of the devilish vices, we devote the first two sections of this paper to a discussion of the elements that figure in Kant's conception of virtue including the dynamics of virtue acquisition and maintenance. Proceeding in this way provides the needed psychological background for understanding Kant's account of the genesis of the devilish vices.

\section{INTRODUÇÃO}

Nos últimos anos, muito foi escrito a respeito das virtudes e das virtudes particulares expostas na ética de Kant, concentrando-se em particular no Tugendlehre, parte II da Metafísica da Moral (ver, por exemplo, Betzler 2008). Menos atenção foi dada ao que Kant tem a dizer sobre os vícios e sobre os vícios particulares. A própria discussão de Kant a respeito dos vícios escolhidos no Tugendlehre é bastante breve, pontuada por observações a respeito das fontes psicológicas de traços de caráter viciosos. Em contraste, o que encontramos em algumas das anotações de aula, é uma discussão consideravelmente rica sobre a psicologia de outros vícios relacionados envolvendo aquilo a que Kant se refere como emulação - um "impulso" implantado na natureza humana que inclina fortemente os homens a serem "iguais aos outros em cada aspecto" (V 27:695). Embora este impulso implantado tenha o bem do auto-melhoramento como seu propósito, sob algumas circunstâncias ele contribui para os vícios diabólicos da inveja, da ingratidão e da Schadenfreude. Nosso objetivo básico aqui é fornecer uma interpretação das ideias de Kant a respeito da psicologia dos vícios diabólicos - 
como indivíduos sucumbem a estes vícios - baseados em observações das Lectures. É de particular interesse em que medida estes vícios compartilham de uma unidade psicológica subjacente, uma afirmação sugerida por algumas das observações de Kant.

Antes de nos voltarmos para a psicologia dos vícios diabólicos, dedicamos as duas primeiras seções deste estudo a uma discussão dos elementos que aparecem na concepção de virtude de Kant, incluindo a dinâmica da aquisição e manutenção da virtude. Proceder desta maneira fornece o background psicológico para se compreender a explicação de Kant sobre a gênese dos vícios diabólicos.

\section{VERDADEIRO AMOR PELA HONRA E A PRÓPRIA AUTO-ESTIMA}

Os rudimentos da concepção de virtude de Kant, importantes para a compreensão da dinâmica de aquisição da virtude, incluem as noções relacionadas de verdadeiro amor pela honra e própria auto-estima. Nossas observações sobre estas noções em Kant são necessariamente breves; não são destinadas a serem uma explicação completa delas e de seu papel na teoria moral de Kant. Antes, pretendemos que nossas observações sejam suficientes para os propósitos de compreender a psicologia dos vícios diabólicos.

Como nossa epígrafe indica, o amor pela honra, enquanto companheiro constante da virtude, é central para a concepção de virtude de Kant. Em nossa compreensão, o amor pela honra é uma virtude que temos o dever de cultivar, de fato Kant afirma que é “o máximo dever da humanidade para com ela mesma" (V 27: 664). Não está inteiramente claro o que Kant quer dizer ao se referir a ela como o mais alto dos deveres para conosco mesmos, mas em uma leitura que tomamos como plausível, este dever nos direciona a 


\section{Dossiê Naturalismo, Dissertatio - Volume Suplementar 02 | UFPel [2015]}

adquirir, ou, mais possivelmente, esforçarmo-nos para adquirir um traço de caráter bastante genérico que desempenha um papel absolutamente central na concepção de virtude de Kant, um papel, como veremos, que não é limitado ao domínio das preocupações morais a respeito de nós mesmos. Permita-nos explicar.

A concepção genérica de virtude de Kant é (como é bem conhecida) o ideal de um agente racional não-santo que cumpre com suas obrigações morais a partir de um senso de dever, ou seja, não apenas as cumpre, mas o faz a partir da única razão motivadora de que tal e tal ação, ou fim, é exigida ou proibida pela lei moral. No Tugendlehre, Kant define a virtude como "a força moral da vontade de um ser humano em cumprir seu dever" (TL 6:405). A força em questão diz respeito à "pureza... de nossa disposição ao dever, a saber, em a lei ser por si só o incentivo, mesmo sem a mistura de objetivos provenientes da sensibilidade, e em ações sendo feitas não somente em conformidade com o dever, mas também pelo dever." (TL 6:446). Esta concepção de virtude especifica o fim "formal" em direção ao qual devemos nos empenhar: uma capacidade desenvolvida de realizar deveres de forma fidedigna a partir do único motivo do dever.

Os fins "materiais" ou substantivos mais genéricos que auxiliam a estruturar nossos esforços para alcançar a virtude são a auto-aperfeiçoamento e a felicidade (moralmente permitida) dos outros. No que diz respeito ao fim do auto-aperfeiçoamento, a virtude a que Kant se refere como amor pela honra representa uma especificação, embora em um nível ainda bastante alto de abstração, do tipo de traço de caráter que deveríamos alcançar ao empenharmo-nos em direção a este fim. Enquanto traço, o amor pela honra envolve essencialmente uma atitude particular em direção a nós mesmos, a qual Kant se refere como própria auto-estima, a atitude que "subjaz à verdadeira honra" (V 27: 667). A própria auto-estima é, podemos dizer, o 
núcleo emocional do amor pela honra enquanto traço de caráter. Portanto, permita-nos examinar melhor a concepção de própria auto-estima de Kant.

Uma seção intitulada "Sobre a Própria Auto-estima" em Collins começa com a observação de que "Esta auto-estoma inclui, por um lado, humildade, e ainda por outro lado, um orgulho verdadeiramente nobre" (C 27: 348). A respeito do tipo de humildade em questão, Kant diz:

Temos uma razão para manter secretamente uma opinião desfavorável de nossa pessoa... Pois se nos compararmos com a santa lei moral, descobriremos o quão remotos estamos da congruência com ela. Esta opinião desfavorável de nossa pessoa surge, portanto, da comparação com a lei moral, e então temos uma razão suficiente para nos rebaixarmos. (C 27:348f)

Como notamos, o conteúdo da lei moral (suas exigências) inclui um dever de auto-aperfeiçoamento - o dever de empenhar-se para se tornar uma pessoa de virtude, o que inclui não somente cumprirmos com nossas várias obrigações morais, mas fazermos isto com base em princípios que compreendemos como sendo soberanamente autoritários. Novamente, devemos nos empenhar para tornar a lei moral um motivo suficiente para cumprirmos com nossos deveres. Assim, nesta passagem a ênfase está no elevado ideal de pessoa - ser uma pessoa de total virtude, uma tarefa a qual, na visão de Kant, está "sempre em progresso" (TL 6:409). Kant pensa que uma avaliação honesta de nossa conduta e caráter em relação a este ideal terá um efeito esmagador em nossa auto-concepção, frustrando não somente a complacência ou indolência moral com relação à meta do autoaperfeiçoamento, mas também frustrando a vaidade moral, um tipo de arrogância. O ponto importante aqui é que o critério único para o tipo de autoavaliação a que Kant se refere como própria auto-estima é a lei moral. Como veremos depois, quando discutirmos os vícios diabólicos, uma falha em 


\title{
Dossiê Naturalismo, Dissertatio - Volume Suplementar 02 | UFPel [2015]
}

compreender esta verdadeira medida da própria auto-estima é central para a explicação de Kant sobre como tais vícios surgem e se estabelecem.

A passagem que estamos examinando prossegue com observações sobre o verdadeiro orgulho nobre.

\begin{abstract}
Mas em comparação com os outros, não temos motivos para manter uma opinião desfavorável sobre nós mesmos, pois posso também possuir valor como qualquer outra pessoa. Esta autoestima em comparação com outros, portanto, é o orgulho nobre. Uma opinião desfavorável de nossa pessoa em comparação com os outros não é humildade; ela denuncia, ao invés, uma alma pequena e um temperamento servil... [Esta] auto-estima é razoável, pois não causamos ao outro qualquer dano por meio dela, se acreditamo-nos iguais a ele em valor. (C 27:349).
\end{abstract}

A base de nossa igualdade com todos outros seres humanos é nossa dignidade enquanto criatura racional, uma condição que está fundamentada unicamente em nossa capacidade de nos darmos leis enquanto agentes racionais autônomos. É algo cuja mera posse não se trata de uma realização, mas uma parte essencial de nossa humanidade a qual a lei moral exige que respeitemos em nós mesmos e nos outros.

Desta forma, o que encontramos nestas duas passagens é uma dupla concepção de auto-estima. Ambas concepções envolvem a lei moral como a única base sobre a qual a própria auto-estima está fundamentada, e assim a lei serve como um critério em relação ao qual nós podemos julgar a própria autoestima ao nos engajarmos em uma avaliação moral honesta de nossa conduta e caráter. O tipo de auto-estima que Kant associa com o orgulho nobre é a que podemos chamar de "auto-estima de reconhecimento". Todos os seres humanos, em virtude de sua condição enquanto seres com dignidade, merecem um certo nível de respeito: estima de reconhecimento. A dignidade em questão 
fundamenta, tanto ontologicamente quando epistemologicamente, a própria auto-estima de reconhecimento.

O tipo de auto-estima relativa à humildade que resulta da comparação de nossa conduta e caráter com o ideal de pessoa é a que podemos chamar de "auto-estima de avaliação". Concordar com as rigorosas exigências do dever fundamenta aquilo a que Kant se refere como o sentido negativo do verdadeiro amor pela honra. É negativo no sentido de que ao concordar com o rigoroso dever (perfeito) nós evitamos ser objeto de nosso próprio desprezo. Ir além das exigências do dever perfeito e engajar-se em ações meritórias de beneficência fundamenta aquilo a que Kant se refere como o sentido positivo do verdadeiro amor pela honra (Ver V 27:665). ${ }^{3}$ Tais ações nos tornam objeto de nossa própria estima positiva.

Dado que um senso próprio de auto-estima "subjaz", como diz Kant, o verdadeiro amor pela honra, podemos notar o seguinte. $O$ verdadeiro amante da honra é uma pessoa que reconhece seu valor enquanto ser com dignidade fundamentada em sua capacidade de dar-se a lei moral. Esta é a auto-estima de reconhecimento. Associado com este verdadeiro amor pela honra está o próprio auto-respeito, o qual resulta da comparação que a pessoa faz de sua conduta e caráter com as exigências do auto-aperfeiçoamento moral estabelecidos pela lei moral, e ao descobrir que ela corresponde mais ou menos ao critério em questão. Esta é a auto-estima de avalição. É claro, quaisquer

\footnotetext{
${ }^{3}$ Nestas passagens, não está completamente claro se o verdadeiro amor pela honra, seja no sentido negativo ou no positivo, requer que nossas ações conferentes de honra sejam feitas unicamente a partir da motivação do dever e, deste modo, não estariam somente de acordo com o dever, mas gozariam de valor moral. Ações que cumprem deveres imperfeitos contam como meritórias na visão de Kant, independentemente se elas são motivadas somente por nosso senso de dever. (Para a defesa desta última afirmação, ver Timmons 2004). Entretanto, como veremos em breve (em uma passagem que citamos), em contraste com o verdadeiro amante da honra, alguém cujas ações obedientes são motivadas meramente pela esperança de ganhar a aprovação alheia é alguém cujas ações carecem de valor moral. Isto sugere que as ações do verdadeiro amante da honra são motivadas pelo dever.
} 


\section{Dossiê Naturalismo, Dissertatio - Volume Suplementar 02 | UFPel [2015]}

auto-avaliações positivas semelhantes devem ser temperadas pelo tipo de humildade que se opõe a auto-complacência moral e à vaidade moral.

Kant contrasta uma pessoa que é um verdadeiro amante da honra com pessoas que possuem um mero desejo pela honra da parte de outros, os quais, em sua análise, constituem uma forma moralmente censurável de ambição. Contrastando o verdadeiro amante da honra com um "aspirante" ou mero caçador de honra, Kant fala sobre o primeiro que "ele se estabelece a partir auto-estima" (V 27:666) enquanto

[o] aspirante da honra, contudo, não se estabelece a partir de princípios e da posse estável destes, mas de meios pragmáticos para tornar as ações nas quais ele assim se engaja reluzentes aos olhos, e extorquir a aprovação de outros, embora sob escrutínio elas percam seu valor moral (V 27: 666).

Além disso, aqueles que meramente desejam ou, como Kant coloca algumas vezes, "imploram" pelo reconhecimento positivo dos outros (C 27:408f), são indivíduos cujo senso de auto-estima está baseado na comparação de seu valor moral ou bem-estar (ou ambos) com suas percepções sobre o valor ou bemestar de outros escolhidos. Este ponto é crucial na compreensão da explicação de Kant sobre os vícios diabólicos. O verdadeiro amante da honra é alguém para quem a lei moral é ela sozinha base para sua auto-estima moral. Como Kant observa em Collins: "a auto-estima moral, a qual está fundada sobre o valor da humanidade, não deve nunca estar baseada em uma comparação com os outros, mas somente em comparação com a lei moral mesma" apesar do fato que "As pessoas estão bastante inclinadas a tomarem os outros como medida de seu próprio valor moral" (C 27:349). Como deveremos ver, tomarmos a condição dos outros como a medida relevante de nossa auto- 
estima é o que leva ao amor pela honra em um "mau sentido", o defeito de caráter central característico dos vícios diabólicos.

\section{A DINÂMICA DA VIRTUDE}

Esta seção será dedicada aos mecanismos psicológicos, incluindo desejos (Trieben), instinto (Instinct) e impulsos (Antrieben) que a natureza implantou nos seres humanos, os quais acarretam diretamente em vir a desenvolver o verdadeiro amor pela honra que está no centro da concepção de virtude de Kant. As três coisas que desempenham um papel na psicologia da virtude (e do vício) de Kant são: o desejo de ser respeitado e os impulsos relacionados associados com a rivalidade e a emulação. Depois de brevemente introduzir estes dons naturais, explicamos sua dinâmica no desenvolvimento de um caráter virtuoso, o qual inclui a necessidade dos indivíduos terem uma concepção de próprio auto-contentamento.

\section{O Desejo de ser Respeitado}

Em uma seção de Collins intitulada "Sobre os Dois Desejos da Natureza, e os Deveres Relacionados a eles" (C 27:407-12), os desejos em questão são: ser respeitado pelos outros e ser amado pelos outros. Kant afirma que o primeiro desejo é tipicamente mais forte, e oferece dois porquês em apoio de sua afirmação. Primeiro, o respeito ou a estima estão propriamente apontados em direção a nosso valor intrínseco, enquanto o amor apenas tem a ver com "o valor relativo dos outros" (C 27:407) o qual presumidamente significa que sermos amáveis é algo que depende de como outros respondem à nossa personalidade geral. A amabilidade, podemos dizer, está nos olhos do observador. Segundo, o respeito "confere maior segurança” (C 27:407) na 


\title{
Dossiê Naturalismo, Dissertatio - Volume Suplementar 02 | UFPel [2015]
}

estima que outros tem por nós, uma vez que ser um objeto de nosso próprio respeito é algo que nos é devido por outros, enquanto ser um objeto de amor (mesmo um objeto de amor próprio) depende, como recém notado, dos sentimentos variáveis dos outros os quais determinam se é o caso que nos acham amáveis. Além disso, estar sujeito ao desprezo por carecer ser digno de respeito é mais doloroso (psicologicamente) do que não ser amado ou ser um objeto de ódio. O significado do desejo de ser respeitado pelos outros concerne a seu propósito:

\begin{abstract}
A Providência implantou esse desejo em nós, para que nossas ações e práticas possam se conformar ao julgamento comum dos outros. Pois se ele nos faltasse, não faríamos nossas ações tão aceitáveis à comunidade. Podemos nos atrapalhar em nossos julgamentos, tal que nossas opiniões geralmente estariam bastante erradas, se elas dependessem somente de nossos próprios juízos. Consequentemente, este desejo nos leva a comparar nossos juízos a respeito de nosso conhecimento com a opinião de outros (C 27:411).
\end{abstract}

A passagem prossegue salientando a importância de comparar nossas opiniões com a "razão universal", a qual é "o tribunal diante do qual nosso conhecimento tem de resistir". (C 27:411). Então, ao menos parte da importância deste desejo, tal como ele se dá no desenvolvimento de nossa virtude, é epistemológico, e está associado com o dever de buscar-se o juízo de (ao menos alguns) outros.

Duas perguntas sobre este desejo e sua importância valem serem feitas. Primeiro, podemos nos perguntar sobre a importância do desejo de ser respeitado pelos outros, uma vez que em outros lugares, Kant deixa claro que "Um amante da honra não encontra em si qualquer necessidade de ser conhecido (não [implora pela fama]); ele não exige ser altamente estimado pelos outros." (V 27:665). Mas como Kant deixa claro nas passagens de Collins 
sob análise, a importância dos outros reconhecerem que nosso amor pela honra está fundamentado na própria auto-estima é devido aos efeitos positivos que geralmente tem sobre a humanidade. Ao contribuir com o que Kant chama de "vínculo moral", todos deveriam se beneficiar da oportunidade de manifestarem não somente um exemplo negativo para os outros, ao fazerem “nada maléfico, mas também fornecer um positivo, ao exibirem um elemento benéfico. Deste modo, nossas ações não devem ser somente boas, mas também devem ser vistas como um exemplo aos olhos dos outros. Elas devem nascer do amor pela honra" (C 27:411f), e ao fazê-lo evitamos a mera aparência de bondade moral, a qual é geralmente motivada por um mero desejo de ser visto pelos outros como digno de extraordinário respeito ou estima e, deste modo, como uma pessoa de superioridade moral. Tal comportamento, incluindo os motivos por trás dele, provavelmente constitui um tipo de ambição repulsiva ou talvez arrogância. Portanto, a importância do desejo de respeito não é meramente epistemológica; as observações que há pouco citamos salientam a importância social deste desejo.

Segundo, uma vez que (como notado acima) a verdadeira auto-estima está propriamente fundamentada unicamente em uma comparação de nosso comportamento, atitudes, e motivos com a lei moral e não na comparação de nós mesmos com outros, podemos nos perguntar se a importância epistemológica do desejo por ser respeitado pelos outros está em conflito com a justa auto-estima. Mas Kant se direciona a esta questão ao afirmar que quando se trata de determinar o princípio do verdadeiro merecimento da honra, não devemos confiar nos juízos de outros:

Com respeito à retidão, a qual compreendo pela minha própria razão, não posso seguir qualquer opinião, mas devo ser guiado pelo meu próprio princípio, conhecido através da razão. Mas se 


\section{Dossiê Naturalismo, Dissertatio - Volume Suplementar 02 | UFPel [2015]}

é uma questão de costume, tenho que ser guiado pela opinião dos outros. (C 27:412)

Presumivelmente, Kant quer dizer que as opiniões dos outros possuem peso epistêmico na auto-avaliação moral somente quando se tratam de particulares que tem relação com a aplicação deste princípio conhecido a priori que determina se, em certos contextos, nossas ações constituem propriamente respeito pela humanidade. Considerações sobre os costumes importam porque eles frequentemente determinam o que conta ou não, digamos, como insulto ou invasão de privacidade. Tais questões empíricas são importantes na aplicação dos, ou ao sermos guiados pelos, princípios básicos da moralidade em circunstâncias particulares. No Tugendlehre, Kant dedica um capítulo bastante breve (TL 6:648f) a esta questão de aplicação no qual ele levanta perguntas acerca de como responderíamos propriamente a pessoas que ocupam diversos papéis, que possuem um caráter moral particular, que se encontram em tais circunstâncias como a prosperidade ou a miséria, e assim por diante.

Uma vez que para nos tornarmos (ou nos empenharmos em nos tornarmos) um amante da honra e desta forma uma pessoa de virtude é necessário conhecer nossas obrigações morais (bem como nos tornarmos propriamente motivados), o propósito epistemológico do desejo por ganhar o respeito de outros tem alguma importância. De maior importância para nosso problema são os estreitamente relacionados instinto de rivalidade e impulso de emulação.

${ }^{4}$ Kant diz "A respeito de suas obrigações naturais, ninguém pode estar errado; pois as leis morais naturais não podem ser desconhecidas de ninguém, ai encontram-se na razão; consequentemente, ninguém está livre de culpa em tal erro, mas a respeito de uma lei positiva há errores inculpabiles [erros de fato], e ai podemos agir em total inocência" (C 27:355). 


\title{
Rivalidade e emulação
}

O instinto de rivalidade (também chamado de antagonismo) envolve uma inclinação profundamente arraigada a nos compararmos com os outros a respeito tanto do mérito moral quando do bem-estar. Este instinto desempenha um papel na psicologia dos vícios diabólicos. Kant escreve que as máximas de vicissitude associadas com estes vícios

\begin{abstract}
Fundamentam sua origem a partir de uma propriedade inata da natureza humana, a qual não apenas nos torna intrinsecamente livres de culpa, mas também nos determina a um propósito admirável: a saber, o instinto [Instinct] do antagonismo ou rivalidade, ou seja, a inclinação a trabalhar contra a perfeição de outros, ou a superá-los através da promoção crescente de nosso próprio cultivo, em concordância com as leis da moralidade. Isto é aparentemente mostrado pelo fato de que constantemente nos comparamos com outros indivíduos, e sentimos desgosto ao descobrimos seus pontos positivos, seja isto sua conduta obediente, sua honra, ou seu bem-estar. (V 27:692)
\end{abstract}

É característico dos vícios manifestos relacionados aos outros, trabalhar contra a perfeição das outras pessoas (seus "pontos positivos"), como por exemplo, no vício da inveja. Em forte contraste a esta manifestação de rivalidade, sua manifestação no cultivo de nossas próprias perfeições em concordância com as leis da moralidade é, veremos, aquilo a que Kant se refere como emulação (Aemulation). Note que a discussão de Kant acerca da rivalidade (ao menos nesta passagem) é algo comum a quando estamos operando contra as perfeições dos outros, o que leva ao vício relacionado ao outro, bem como a nos engajarmos em um regime de emulação. Ou seja, a rivalidade como aqui compreendida não necessita ser algo maldoso; há algo como a rivalidade amigável, mesmo se isto envolver algum desconforto ou dor ao vermos outros como, de alguma maneira, superiores a nós mesmos. Aristóteles mostra bem esta questão ao comparar a emulação com a inveja: 


\title{
Dossiê Naturalismo, Dissertatio - Volume Suplementar 02 | UFPel [2015]
}

\begin{abstract}
A emulação é dor causada ao vermos a presença, em pessoas cuja natureza é como a nossa, de coisas boas altamente valiosas e que são possíveis para nós alcançar; mas isto é sentido não porque os outros possuem estes bens, mas porque nós mesmos não os possuímos. É, portanto, um bom sentimento sentido por boas pessoas, ao passo que a inveja é um mau sentimento sentido por pessoas más. A emulação nos faz tomar medidas para assegurarmos as boas coisas em questão, a inveja nos faz tomar medidas para que o próximo deixe de tê-las. (Rethoric, Bk. II, 11, 30-8 [Mckeon 1941, 1402]).
\end{abstract}

Mas note também que na passagem de Vigilantius acima, Kant menciona o desgosto (algo doloroso) que sentimos em comparações que levam à rivalidade. A inveja tem como alvo, por assim dizer, a preservação de nosso senso de auto-estima - não somente enquanto um indivíduo em pé de igualdade com os outros, mas também enquanto um indivíduo que clama por estima de avaliação de outros independentemente de sermos dignos de tal estima. É a preservação de nosso senso de auto-estima que move os vícios diabólicos.

Contudo, é importante tomar nota de uma distinção que está implícita no uso que Kant faz do termo 'emulação'. Em alguns lugares, Kant se refere à emulação como um impulso (Trieb) implantado na natureza humana cujo propósito "assenta realmente em incitar os homens ao cultivo constante da mais elevada perfeição deles mesmos, pela comparação com os outros ( $V$ 27:678f)". Desta maneira, é algo a ser cultivado para este propósito. Mas ele também nota que este impulso pode levar ao tipo de rivalidade na qual operamos contra as perfeições (e/ou o bem-estar) dos outros, um resultado da emulação que ele descreve como "um lado da natureza humana que se tornou maligno" (V 27:678). Portanto, a emulação enquanto um impulso está intimamente relacionada ao instinto da rivalidade. Aqui está como compreendemos sua conexão. A emulação necessariamente envolve a 
comparação de nós mesmos com os outros. Esta comparação desencadeia o instinto da rivalidade nos casos em que sentimos desgosto enquanto resultado de ver o outro grupo como possuindo "bens" os quais nos faltam. Esta rivalidade pode servir ao propósito da emulação ao tomar a forma de empenho para sermos como a outra pessoa em algum aspecto ao nos engajarmos em algum regime com o objetivo de melhorarmos em direção ao que quer que seja que vejamos como faltante em nós e, deste modo, nos elevamos até o nível da outra pessoa, quando não superamos ele ou ela. Mas a rivalidade também pode tomar uma forma maligna, levando a um ou outro vício.

A rivalidade, então, pode servir a um bom propósito, a saber, estimulando-nos a emular nosso rival ao aprimorarmos nossa própria condição, seja ela nosso caráter ou outros benefícios. É claro, ao seguir uma trajetória de auto-melhoramento não significa que estejamos fazendo isto a partir de um verdadeiro amor pela honra. Podemos estar nos empenhando para emular nossos rivais porque somos alguém que apenas implora pela honra. Contudo, a motivação própria guiando a emulação deveria ser nosso amor pela honra, o qual, diz Kant, está "impresso" em cada indivíduo e é “a fonte e princípio que encontra expressão na emulação - "um desejo de continuamente nos aperfeiçoarmos em comparação com os outros" (V 6:680). Presumivelmente, por conta do amor pela honra (em um sentido a ser contrastado com o amor pela honra enquanto virtude adquirida) estar "impresso", ele funciona como uma fonte motivacional de emulação - uma inclinação (anseio habitual) a ser ao menos igual aos outros naqueles aspectos merecedores de aprovação. Por conta do amor pela honra (em contraste com um clamor por reconhecimento externo não-merecido) ter como seu objeto a própria auto-estima, e deste modo a comparação com a lei moral enquanto medida desta estima, ele serve como um princípio guiando a emulação. 


\section{$\underline{\text { Dossiê Naturalismo, Dissertatio - Volume Suplementar } 02}$ | UFPel [2015]}

Somando-se ao desejo por ser respeitado, o instinto da rivalidade, e o impulso da emulação, há mais um ingrediente essencial à dinâmica das virtudes na teoria de Kant, para o qual agora voltamo-nos.

\section{Próprio auto-contentamento}

Como observado anteriormente, um elemento importante em vir a ser um amante da honra é ter um senso próprio de, e controle sobre, nossa felicidade a qual, diz Kant, está fundada sobre "estarmos contentes com nós mesmos" (V 6:649). O contentamento em questão requer não permitir que nossas necessidades se ampliem para além daquilo que seja realmente necessário para evitar doenças físicas e psicológicas, e assim tomar conta de nossas necessidades enquanto ser físico; e em particular não deixar que "amenidades da vida" se tornem necessidades (ver V 27:646-57, \ 104 e 106). Nestas passagens, Kant menciona um "princípio de máxima dispensabilidade" a respeito das amenidades da vida o qual é resumido pela regra: "tente manter sua condição tal que dispenses tudo o quanto for necessário para estabelecer seu contentamento sobre as menores condições possíveis". (V 6:649, ver também C 27:392-406). O que Kant está defendendo nestas passagens é a importância de vir a adotar uma atitude de auto-contentamento com respeito a nosso bem-estar ou felicidade que não abale nossa aspiração ao verdadeiro amor pela honra, e então vir a estabelecer-se sobre uma concepção de nossa felicidade que esteja dentre os limites da razão moralmente prática. Como deveremos ver a seguir na seção 3, este ingrediente é um elemento psicológico crucial na evitação do vício.

Agora nos encontramos em posição para caracterizar, em um nível de descrição geral, a psicologia da aquisição e manutenção da virtude, ou ao menos o curso estável do progresso em direção ao ideal moral de auto- 
aperfeiçoamento de Kant. O que aprendemos a partir das Lectures, como há pouco notado, é que há certos desejos e impulsos naturais cujo funcionamento adequado é importante para nos engajarmos com sucesso no projeto de autoaperfeiçoamento. O processo geral em questão é inquestionavelmente social. Para ser uma pessoa virtuosa, precisamos do tipo de compreensão moral que o desejo por ser respeitado pelos outros provoca, ou seja, consultar os juízos morais de (certos) outros. Saber que nosso dever é parte da virtude moral (TL 6:446). Mas o auto-aperfeiçoamento e, deste modo, a virtude também requerem que nos engagemos em nos comparar com os outros - o resultado do impulso à rivalidade - cuja manifestação enquanto emulação guia-nos em direção a desenvolvermos aqueles traços que contribuem para a virtude. Especificamente, através da emulação em casos onde estamos focados nas qualidades morais de nossos rivais, somos motivados a adquirir ou desenvolver mais plenamente as virtudes morais, mas não porque estamos em competição com nossos rivais. A base própria para se julgar as qualidades de nosso caráter moral é o ideal da humanidade prescrito pela lei moral. O papel de outros escolhidos em relação à nossa busca da virtude é o de servirem para tornar manifestos por meio de exemplos os tipos de comportamento e atitudes que deveríamos lutar para adquirir ou desenvolver mais plenamente. Emular os outros para este propósito é um elemento essencial em nossa busca humana por virtude 5 .

Como antes notado, o instinto de rivalidade também envolve a comparação com os outros a respeito de nosso próprio bem-estar. E a menos que sejamos capazes de estarmos contentes na vida sem precisar das amenidades as quais os outros podem apreciar, incluindo o desejo de adquirir bens materiais, ou ter certos poderes sobre outros, ou o que quer que seja, o provável descontentamento que surge de não ter tais coisas tenderá a

\footnotetext{
${ }^{5}$ Kant afirma que fazer tais comparações é um dever. Ver V 27:703f.
} 


\section{Dossiê Naturalismo, Dissertatio - Volume Suplementar 02 | UFPel [2015]}

interromper o funcionamento adequado da emulação. $O$ contentamento próprio com nossa prosperidade requer as assim chamadas virtudes estruturais - virtudes que concernem aos "tipos de força no auto-governo racional"6. Estas incluem virtudes cuja posse não serve somente para controlar nossas inclinações de modo que não se tornem necessidades, mas também para ganhar domínio sobre nossas emoções e paixões. Em alguns lugares, Kant se refere ao dever (e à virtude correspondente) do auto-domínio, caracterizada (enquanto dever) como "comando positivo para um ser humano, nomeadamente para subordinar todas suas capacidades e inclinações a seu controle (de sua razão), e deste modo governar a ele mesmo" (TL 6:408)7 ${ }^{7}$. A frugalidade, "moderação ou abstinência" na posse de bens materiais está entre as virtudes mais específicas contribuindo para este tipo de domínio (C 27:406, ver também V 27:696). E esta virtude em particular tem como uma de suas regras específicas o que identificamos anteriormente com o princípio da máxima dispensabilidade - prescindindo do "quanto for necessário para estabelecermos seu contentamento sobre as menores condições possíveis". (V 6:649). Portanto, os elementos que aparecem na psicologia da aquisição e manutenção da virtude - sua dinâmica - envolvem o seguinte:

- Precisamos de um entendimento da própria auto-estima (enquanto um agente com dignidade e enquanto um ser imperfeito que é avaliado por si mesmo por suas ações e caráter), a qual diz respeito à lei moral. $\mathrm{O}$ reconhecimento de nós mesmos enquanto capazes de nos darmos a lei moral e consequentemente o reconhecimento de nossa dignidade, fundamentam a auto-estima de reconhecimento. A comparação de nosso comportamento e caráter moral com as

${ }^{6}$ Adams 2006, 37. Seguindo Roberts 1984, Adams contrasta virtudes estruturais com virtudes motivacionais.

${ }^{7}$ At TL 6:408, Kant dintingue o dever positivo do auto-domínio do dever negativo da apatia "que o proíbe de permitir ele mesmo ser governado por seus sentimentos e inclinações." 
demandas da lei moral com respeito ao ideal de humanidade (um ser humano perfeito), fundamentam a auto-estima de avaliação.

- Também são necessários juízos confiáveis sobre a qualidade moral de nosso comportamento e atitudes que requerem que comparemos nossas próprias opiniões com as de outros a fim de guiar nosso progresso - algo que o desejo por ser respeitado nos inclina a fazer.

- Além disso, a comparação com outros a respeito do mérito moral e bem-estar para propósitos de auto-aperfeiçoamento é importante. Tal comparação recorre ao impulso de emulação, e em uma boa pessoa resulta em empenharmo-nos por tais coisas de valor (moral e não-moral) que os outros possuem (ou tem em maior medida), mas as quais atualmente nos faltam.

- A fim de que tudo isto funcione adequadamente, devemos ter a concepção de bem-estar e uma visão correspondente de uma vida contente que não esteja em tensão com o empenho pelo autoaperfeiçoamento.

- Por fim, a fim de que compreendamos aquilo que constitui uma vida contente ser convertida em comportamento, devemos possuir a virtude estrutural geral do auto-domínio e as virtudes mais específicas tais como a frugalidade que contribuem para o autodomínio.

Quando todos elementos estão em bom estado de funcionamento, nos movemos na direção do ideal de perfeição moral que constitui a virtude. Possuímos a virtude do amor pela honra. Mas as coisas podem dar errado.

\section{A EMULAÇÃO E OS VÍCIOS DIABÓLICOS}




\title{
Dossiê Naturalismo, Dissertatio - Volume Suplementar 02 | UFPel [2015]
}

Não está inteiramente claro nos textos que consultamos o que é que há na inveja, na ingratidão e na Schadenfreude que as torna diabólicas. Em Collins, encontramos estas observações:

\begin{abstract}
Todas três, ingratidão (ingratitudo qualificata) [ingratidão agravada, ódio a um benfeitor], inveja e Schadenfreude, são vícios diabólicos porque elas evidenciam uma inclinação imediata para mal. Que o homem deva ter uma inclinação indireta para o mal é humano e natural; o avarento, por exemplo, gostaria de obter tudo; mas ele não tem qualquer prazer pelo fato de outros não terem absolutamente nada. Há vícios, portanto, que são maus tanto direta quanto indiretamente. Estes três são aqueles que são diretamente maus (C 27:440). ${ }^{8}$
\end{abstract}

Nesta passagem, a ênfase está na inclinação a alguma forma de outro mal dirigido por nenhum motivo adicional. Este parece ser o sentido no qual a inclinação ao mal característica da diabolicidade é imediata. Então, por exemplo, nas notas de Herder, encontramos esta observação: "Um prazer direto pelo infortúnio alheio é diabólico" (H 27:5) ${ }^{9}$. A diabolicidade aqui aparentemente consiste em ter prazer não-derivado com o estado de coisas da perda de outra pessoa.

Mas note a referência ao ódio na citação acima. Aparentemente alguém poderia ter uma inclinação imediata a ter prazer pelo infortúnio de outra pessoa sem odiar a pessoa. Um episódio de raiva direcionada a outra pessoa pode fazer com que tenhamos um prazer passageiro imediato pela outra pessoa estar passando por um infortúnio. Talvez estes vícios enquanto traços e sua manifestação no pensamento e comportamento não precisem incluir o ódio para serem diabólicos. Podemos supor, então, que o ódio apenas

80 conteúdo entre colchetes é a nota de rodapé da expressão em latim.

9 Ver também a observação de Kant em Collins (C 27:439) sobre a diferença entre ter uma atitude invejosa com respeito às vantagens de outro e ter uma atitude de inveja com respeito a tais vantagens. 
contribui para o nível de diabolicidade manifestado em certos casos de inveja, ingratidão e Schadenfreude uma vez que Kant mantém que a diabolicidade desses vícios permite gradações.

Mas então, novamente, talvez o ódio seja essencial para a posse de um desses vícios considerados diabólicos. A raiva é aquilo a que Kant se refere como um afeto, ao passo que o ódio é uma paixão, e da seguinte citação pareceria que uma paixão é aquilo que é essencial ao vício para que seja "propriamente" mau.

Uma paixão é um desejo sensível que se tornou uma inclinação duradoura (por exemplo, o ódio, enquanto oposto à raiva). A calma com que nós nos entregamos a ela permite a reflexão e autoriza a mente a formar princípios sobre ela e assim, se a inclinação ilumina algo contrário à lei, para aninhar-se sobre ela, para enraizá-la profundamente, e para assim apanhar o que é mau (enquanto algo premeditado) em seu máximo. E o mau é então propriamente mau, ou seja, um verdadeiro vício (TL 6:408).

Então, talvez seja somente quando a posse da inveja, da ingratidão, e da Schadenfreude enquanto traços e seus episódios correspondentes envolvem o exterior e externalizam o ódio pelo outro que elas são diabólicas ${ }^{10}$. Quando fala de sua natureza diabólica, Kant descreve tais traços e episódios correspondentes como diretamente contrários a uma atitude humana com relação aos outros. De fato, ele observa, por conta de "serem diretamente opostas à simpatia moral, [eles] "indicam inumanidade" (V 27:692). A simpatia, para Kant, é um sentimento, e segundo o que parece o que está diretamente

\footnotetext{
10 No Tugendlehre, a inveja enquanto traço de caráter é caracterizada como envolvendo "uma propensão a ver o bem-estar dos outros com angústia, ainda que não nos afaste do nosso próprio" (TL 6:458). Kant diz que esta propensão a ver o bem-estar de outros com angústia é somente uma "disposição indiretamente malevolente", provavelmente porque ela não envolve (ou não precisa de) uma inclinação imediata a afetar negativamente o bem-estar da pessoa a qual invejamos ou ao ódio da pessoa invejada.
} 


\section{$\underline{\text { Dossiê Naturalismo, Dissertatio - Volume Suplementar } 02}$ | UFPel [2015]}

oposto a este sentimento é o sentimento (paixão) de ódio. Além disso, Kant deixa claro que nem todos episódios destes vícios são diabólicos: é somente ao "atingir sua altura máxima, [que] estes vícios são diabólicos" (C 27:439). Pensamos que estas considerações sugerem fortemente que o ódio é um elemento essencial que contribui para tornar uma instância de um vício, que de outra maneira seria não-diabólico, em algo diabólico. A ideia em conexão com a inveja seria que uma inclinação imediata para sentir desprazer pela vantagem de outro, acoplada com o ódio por aquela pessoa, é o que torna instâncias particulares da inveja diabólicas. Em apoio a esta interpretação, considere esta observação sobre a ingratidão:

Se esta ingratidão crescer tanto que ele não possa aguentar seu benfeitor, e se tornar seu inimigo, este é o grau diabólico do vício, uma vez que é completamente repugnante para a natureza humana, odiar e processar aqueles que fizeram a nós uma gentileza. (C 27:439)

Uma vez que a diabolicidade admite graus, poderíamos manter que o ódio é essencial às ocorrências diabólicas destes vícios enquanto também mantermos que a intensidade de nosso ódio afeta seu grau de diabolicidade.

Por fim, há outro fator que pertence ao grau de vicissitude (se não de diabolicidade) do vício. Quando se trata de manifestações dos vícios da inveja, ingratidão e Schadenfreude no pensamento e no comportamento, é importante manter em mente a diferença entre as atitudes de desejar, querer, pretender (adotar uma máxima), e agir de acordo com nossa máxima. Podemos querer que a pessoa que invejamos encontre o prejuízo e o infortúnio sem adotarmos a máxima de causar prejuízo a ela e, desta maneira, sem formar a intenção de fazer tal coisa. E certamente, adotar uma máxima fundamentada na inveja é pior do que querer meramente que algum infortúnio se suceda à pessoa 
invejada. Além disso, agir de acordo com nossa máxima, a qual Kant se refere como própria inveja, pareceria manifestar um grau maior de vicissitude do que ter a máxima mas nunca agir de acordo com ela (cf. TL 6:458). Então há graus de inveja que variam, desde desejar ou querer que o objeto de nossa inveja seja privado de vantagens seletas que invejamos, até manifestações mais viciosas do vício. E, é claro, o mesmo pode ser dito sobre a ingratidão e a Schadenfreude. Se nem todos casos de desejar, querer, pretender e agir que manifestam um destes vícios precisam ser diabólicos, então podemos traçar uma distinção entre graus de vicissitude e graus de diabolicidade, embora talvez, por exemplo, se nossa atitude invejosa nos leva a nos engajarmos em uma ação danosa, a partir da inveja (própria inveja), é muito provável que nossa inveja envolva aqueles elementos que tornam nossas ações diabólicas.

Portanto, com respeito aos vícios diabólicos de Kant, temos estas questões. Dado que nem todos casos destes vícios (enquanto traços) e seus episódios emocionais associados são diabólicos, o que distingue os casos nãodiabólicos dos casos diabólicos? Ademais, uma vez que a diabolicidade de um vício é uma questão de grau, qual fator (ou talvez fatores) afetam seu grau de diabolicidade? Em resposta, aqui estão nossas tentativas propostas. Primeiro, estamos inclinados para a opinião de que o ódio é o elemento nos vícios diabólicos de Kant que está sendo genuinamente diabólico. Segundo, um fator que afeta o grau de diabolicidade manifestado nestes vícios é a intensidade de nosso ódio. Talvez outro fator (sem dúvida relacionado ao primeiro) é a atitude manifestada em episódios do vício e em particular se agimos a partir de nosso ódio ${ }^{11}$.

Permita-nos nos voltarmos agora para a psicologia destes vícios, começando com a inveja.

11 Embora, como notado, permitamos que se possa distinguir graus de vicissitude de graus de diabolicidade. 


\section{Dossiê Naturalismo, Dissertatio - Volume Suplementar 02 UFPel [2015]}

\section{Inveja}

Casos de inveja, na perspectiva de Kant, envolvem não querer que outros escolhidos tenham quaisquer "vantagens" que possuam, as quais atualmente nos faltem ${ }^{12}$. O homem invejoso quer ser feliz quando todos ao seu redor estiverem infelizes, e busca a docilidade da felicidade nisto, que ele desfrute dela sozinho, e que todos outros estejam infelizes". (C 27:438). Como é que surge a inveja?

Kant escreve que "A inveja possui seu fundamento imediato na emulação", a qual, é claro, se refere ao impulso de emulação que nos impele a nos compararmos com os outros. Como notamos, o propósito deste impulso é nos estimular a cultivar aquelas perfeições que contribuem para nosso caráter e circunstâncias gerais. E, tal como conhecemos a partir da ênfase de Kant sobre a importância epistemológica da comparação eu-outros, tudo corre bem contanto que tenhamos uma compreensão da própria auto-estima a qual envolva comparar nossa conduta e caráter com os padrões de perfeição tais como estabelecidos pela lei moral - o "método" que é característico ao amante da honra.

Mas [no caso dos vícios diabólicos] é aqui onde se encontra o erro. Tal método [reflexão sobre e comparação com a lei moral] estabeleceria o verdadeiro amor pela honra em nós. Mas ao julgar a si mesmo e ao seu valor intrínseco, o homem o funda e

\footnotetext{
12 Meramente desgostar do fato de outros terem tais vantagens não se qualifica como inveja. Tal desgosto é um vício, mas é o vício "humano" do begrudgement. E note que desgostar o estado de coisas em questão não é o mesmo que querer que os outros não tenham quaisquer vantagens que suceda deles gozarem e que nos falte. É quando este desgosto se intensifica até um desejo de que outros sejam privados de tais vantagens que o mero begrudgement se intensifica até a inveja. Em alguns lugares Kant faz a consideração de que o que é particularmente diabólico sobre este vício é que "Dizemos sobre o begrudgement que um homem pode não suportar qualquer um feliz acima dele, mas sobre a inveja, que ele não pode suportar qualquer um feliz ao seu lado (V 27:698).
} 
o mede ao invés, sobre uma estimativa meramente comparativa de sua pessoa e condição contra o valor e condição de outro homem. Consequentemente surge o amor pela honra em um mal sentido: se ele se encontrar rebaixado pela comparação com o outro, isto desperta nele aversão pela outra pessoa, e ao invés de ativamente esforçar-se para se tornar igual em valor com o outro, ele sucumbe ao ressentimento pelo ao valor e mérito do outro, ou tenta diminuí-lo (V 27:695).

Então o impulso da emulação, junto de uma má compreensão da própria autoestima (e assim uma falha em ser um amante da verdadeira honra), estão no coração da psicologia da inveja. Podemos trazer a foco os vários elementos da psicologia deste vício ao estabalecer os vários estágios até sua completa manifestação diabólica.

- Estágio da Emulação-Comparação: levado pelo impulso da emulação, nos comparamos com os outros em respeito às características com as quais nos importamos particularmente porque tomamo-las como estando relacionadas à nossa auto-estima. Neste estágio, percebemos as desigualdades entre nós e o outro, de um ou outro tipo.

- Estágio da Rivalidade: devido ao fato de que estamos focados em vantagens que os outros possuem e que nos faltam, isto induz a um sentimento de desgosto o qual desencadeia o instinto de rivalidade.

- Estágio de avaliação-decisão: o desgosto que sentimos (algo desagradável) é uma reação emocional a uma ameaça percebida à nossa auto-estima porque baseamos nossa auto-estima inteiramente na comparação com os outros (ao invés de na lei moral) e assim "nos encontramos rebaixados pela comparação com o outro" (V 27:695). Esta avaliação não somente leva a sentir aversão do fato de que há alguém que está acima de nós (begrudgement), mas sobre a base desta avaliação dolorosa, junto com outros fatores 


\section{Dossiê Naturalismo, Dissertatio - Volume Suplementar 02 | UFPel [2015]}

contribuintes (fatores que tem a ver com não ser inoculado contra o vício), somos levados a decisão de que "a fim de tornar-se igual com ele [nosso rival] ... [nos lançaremos à] "destruição do bem-estar do outro, para torná-lo menos afortunado do que nós mesmos" (V 27:693). Quando nossa hostilidade direcionada aos outros se torna ódio de nosso rival, nossa inveja é diabólica.

- Estágio de hostilidade direcionada aos outros: Esta decisão nos leva a nos engajarmos em hostilidades direcionadas aos outros que são características daquilo a que Kant se refere como "própria inveja".

É no estágio de avaliação-decisão que se encontra o erro.

Contudo, estes estágios não revelam detalhes sobre a maneira específica pela qual podemos sucumbir ao vício da inveja. Dado que há duas concepções de auto-estima (de reconhecimento e de avaliação), ambas as quais estão propriamente fundamentadas em compreendermos a importância de e comparar-nos com a lei moral, e dado que, falando de maneira ampla, podemos sentir inveja da posição moral de outrem ou do bem-estar de outrem, ou ambos, há várias formas específicas nas quais este vício pode se manifestar. Aqui estão alguns exemplos.

Um caminho começa pela auto-estima deficiente - pela auto-estima que devemos ter em virtude de sermos autônomos, algo que dividimos com todos os outros apesar de nossa conduta ou caráter e em virtude da qual desfrutamos de uma posição moral igual a dos outros. Se nos sentimos rebaixados em nossa posição moral comparado aos outros por conta de suas amenidades não-morais, então temos uma falsa visão de posição moral: todos estão em pé de igualdade dado a autonomia. As amenidades dos outros não são uma base relevante de comparação. $\mathrm{O}$ mesmo pode ser dito por se sentir rebaixado por conta dos méritos morais de outrem. 
Se nos sentimos rebaixados na auto-estima de avaliação por conta das amenidades dos outros, então é provável que falhemos em ter um senso adequado de auto-contentamento não-moral; permitimos que nossa concepção de felicidade verdadeira seja refém de coisas, talentos ou posições que não são necessidades na vida. E, em qualquer caso, a auto-estima de avaliação própria tem a ver com completar exigências morais e performar ações moralmente meritórias. É claro, podemos não ser invejosos dos outros porque eles desfrutam de todos os tipos de amenidades na vida; podemos invejá-los ao invés porque eles não estão no tipo de circunstâncias infortúnias nas quais nos encontramos. A respeito deste tipo de situação, em Collins encontramos esta observação sobre a inveja e nossas fortunas na vida: "Para manter a alma livre do vício da inveja, devemos, portanto, suportar cada dificuldade, e, uma vez que isso nos tenha sucedido, extrair disto o benefício que sempre reside no infortúnio" (C 27:368).

Se nos sentimos rebaixados na auto-estima de avaliação por conta dos méritos morais superiores de outrem, é fantasia supor que podemos restaurar nossa auto-estima e assim preservar um verdadeiro senso de honra ao fazer algo prejudicial para sua posição moral que os rebaixa. Rebaixar a outra pessoa não restaura ou preserva a própria auto-estima. Novamente, a auto-estima de avaliação própria é algo que ganhamos ao cumprirmos com ou ultrapassar as rigorosas exigências da lei moral.

\section{Ingratidão}

O perfil psicológico deste vício segue o mesmo padrão que o da inveja ${ }^{13}$. O erro ocorre no estágio de avaliação-decisão. A diferença essencial, é claro, é que nos sentimos rebaixados pelo nosso benfeitor como o resultado da

\footnotetext{
${ }^{13}$ Discutimos a psicologia da ingratidão em Smit and Timmons 2011.
} 


\section{Dossiê Naturalismo, Dissertatio - Volume Suplementar 02 | UFPel [2015]}

relação beneficiado-benfeitor. A ingratidão envolve "um desprazer ou descontentamento na obrigação que o outro colocou em nós, através da bondade que ele mostrou com relação a nós" (V 27:694f). Novamente, a fonte deste vício é uma concepção falha de nossa auto-estima, como Kant torna claro nesta passagem:

O fato de que outros fizeram mais por nós do que precisam fazer desperta a ingratidão; pois todo seu mérito com respeito à outra pessoa, ou fortunas, ocasiona que somos deste modo gratos a ele por conta disto; mas nisto ele teve uma influência em nosso bem-estar, ele tem uma vantagem sobre nós, pela qual ele é elevado sobre nosso valor e nós, ao contrário, nos tornamos inferiores neste quesito; pois supondo que a estimação de nós mesmos assenta em um juizo comparativo com o valor do outro, esta degradação nos desagrada; somos torturados pela obrigação que ele depositou em nós, e então a inveja impede nossa participação e interesse em seu bem-estar (V 27:695f, nossa ênfase imediatamente após o ponto e vírgula).

Novamente, Kant é claro nas notas de Collins sobre este vício não precisar ser diabólico. Ao considerar a questão sobre se "a alma humana contém uma inclinação imediata para o mal, e assim, uma propensão para o vício diabólico", Kant se pergunta se uma pessoa pode "ser tão ingrata como se realmente odiasse seu benfeitor" uma vez que casos de ingratidão podem envolver somente ser "demasiado orgulhoso para ser grato [a nosso benfeito], e de resto, desejar a ele toda felicidade; o único detalhe é que, ele gostaria de estar bem longe de seu caminho" (C 27:440f). Tais casos de ingratidão não são diabólicos, embora moralmente objecionáveis. Com respeito aos casos diabólicos (e o traço associado de ingratidão), há espaço para, como antes explicado, admitirmos graus de diabolicidade.

\section{Schadenfreude}


Kant afirma que todos os três vícios diabólicos "tem sua origem em uma tendência inata de nos estabalecermos em contraste com a superioridade do outro". (V 27:695); rivalidade, em outras palavras. Portanto, como a inveja e a ingratidão, manifestações típicas da Schandenfreude envolvem nossa comparação com os outros. O espaço não nos permite examinar esta psicologia da Schadenfreude tal como Kant a vê; nos limitamos a algumas observações.

Em Vigilantius, Kant associa este vício com a inveja. "A Schadenfreude (vugaris) é a malevolência ou júbilo frente ao infortúnio do outro, os quais parecem, portanto, estarem fundados na inveja, ou descontentamento com sua felicidade" (V 27:695). Contudo, o termo "parecem" nesta passagem lança dúvidas sobre se Kant está dizendo que a Schadenfreude realmente está fundada na inveja. Além disso, não está claro que sentido de "fundados" é usado nesta passagem. Isto significa que uma explicação geral de sua gênese psicológica recorrerá ao vício da inveja? Parece improvável. Em nenhum lugar das Lectures on Ethics no trabalho publicado de Kant encontramos a defesa desta afirmação. Além disso, em Collins (C 27:441) Kant afirma que este vício é geralmente “já fortemente aparente na juventude" quanto eles se engajam em certas formas de travessuras. Ele observa que esta inclinação em ter júbilo pela aflição de outrem é "um tipo de animalidade, pela qual o homem retém algo da besta nele, a qual não pode superar. Não conhecemos a fonte disto, e por algumas de nossas características não podemos aduzir qualquer razão que seja”. Não há menção à inveja aqui ${ }^{14}$. O que parece plausível é que alguém que é invejoso dos méritos de outrem, seja em querer ou desejo, muito provavelmente sentirá prazer no fato do objeto de sua inveja perder os méritos que ele inveja. A

\footnotetext{
${ }^{14}$ Contudo, alguns teóricos das emoções distinguem formas primitivas de formas sofisticadas de várias emoções, incluindo a inveja, e também pode ser o caso de que uma forma de inveja é a base do tipo de maldade a qual Kant está se referindo. Na distinção primitivo/sofisticado a respeito da inveja e do ciúmes, ver Taylor 1988.
} 


\section{Dossiê Naturalismo, Dissertatio - Volume Suplementar 02 | UFPel [2015]}

Schadenfreude é uma companhia natural da inveja, mas não podemos sentir júbilo pelos infortúnios de outrem sem primeiro invejá-lo.

Então, permita-nos deixar esta passagem de lado e focar na observação de Kant a respeito dos vícios diabólicos resultantes de uma tendência inata a nos opormos à superioridade dos outros. Aqui nos focamos por um momento nas passagens do Tugendlebre. Ao discutir o vício da malícia, “o oposto direto da simpatia" (TL 6:459) o qual envolve o Schadenfreude em seu núcleo, Kant observa: "É, de fato, natural que, pelas leis da imaginação (a saber, a lei do contraste) sentimos mais fortemente nosso próprio bem-estar e mesmo nossa boa conduta quando o infortúnio de outros ou sua queda em desonra são colocados ao lado de nossa própria condição como uma lâmina para mostrá-lo na luz mais brilhante" (TL 6:460). Mas de que maneira este foco em nosso próprio bem-estar comparativo ou mérito moral se transforma em ter prazer imediato pelos infortúnios dos outros, onde o foco de preocupação mudou de nós para os outros? Nesta mesma passagem, Kant parece estar se dirigindo a esta questão:

É arrogância dos outros quando seu bem-estar é ininterrupto, e é sua presunção em sua boa conduta (falando estritamente, somente em sua boa fortuna ao ter escapado até então às tentações do vício público) - ambos os quais um egoísta considera como seu mérito - que geram este júbilo malevolente. (TL 6:460)

Estas observações sugerem que ao menos uma fonte característica de Schadenfreude é uma resposta àquilo que julgamos ser a pressuposição não justificada de superioridade pela parte dos outros. Nosso ressentimento natural de tais pessoal possivelmente desencadeia uma aversão imediata a eles, e talvez justificadamente. Mas Kant distingue aversão de má vontade, a última caracterizada enquanto ódio de outros que inclui o vício da Schadenfreude (C 27:430-2). Se focamos nas observações sobre a arrogância e a presunção, então 
podemos ver como nosso perfil psicológico da inveja e da ingratidão também se ajusta ao vício do júbilo malicioso. O estágio de emulação-comparação: o impulso da emulação nos incita a nos compararmos com os outros, particularmente naquilo que é devido a nossa auto-estima. O estágio de rivalidade: a exibição de traços como a arrogância e a presunção em outros, os quais naturalmente interpretamos como planejados por eles para afirmarem sua superioridade sobre nós, desencadeiam o instinto da rivalidade. $\mathrm{O}$ estágio de avalição-decisão: por conta de nossa auto-estima ser inteiramente embasada na comparação com os outros, sua atitude de superioridade resulta em virmos a ter uma má-vontade com relação a eles, a qual inclui uma disposição a termos júbilo malicioso em quaisquer infortúnios que eles venham a sofrer. Estágio de hostilidade direcionada para os outros: nossa má-vontade nos leva a nos engajarmos em hostilidades direcionadas para os outros e, por conseguinte, no que Kant chama de "malícia própria” (TL 6:460).

Não há menção à inveja nesta história, e de fato, não precisamos ser invejosos daqueles que demonstram arrogância ou presunção reprovável. Este perfil psicológico é geral o suficiente para abranger todos os casos deste vício? Certamente casos deste vício não são apontados somente em direção ao arrogante, e parece implausível que a Schadenfreude sempre se inicie com hostilidade em relação ao arrogante e então se enraíze em nossa personalidade. Obviamente, há mais trabalho interpretativo para se fazer na exploração da psicologia deste vício no pensamento de Kant. Mas deixamos este trabalho para outra ocasião.

Por fim, como os dois outros vícios diabólicos, há casos de genuína Schadenfreude que não são diabólicos. Kant nota que "a Schadenfreude... não está sempre enraizada na maldade... [porque] ela geralmente possui sua fonte na mera travessura, alegria pelos percalços alheios” (V 27:698). Ele dá alguns exemplos, incluindo "alegrar-se com a queda do outro como se fosse de uma 


\section{Dossiê Naturalismo, Dissertatio - Volume Suplementar 02 | UFPel [2015]}

piada, e o medo malicioso de que os outros divirtam-se com sua agitação". Ele afirma que "há em todos estes casos uma Schadenfreude eticamente reprovável" (ibid), apesar de não serem diabólicos, uma vez que sentir alegria pelos percalços alheios não precisa indicar uma inclinação imediata para o mau que expresse ódio direcionado aos outros. A respeito dos casos diabólicos deste vício, eles ocorrem em graus sujeitos aos mesmos fatores que determinam os graus de diabolicidade manifestados em casos de inveja e ingratidão.

\section{CONCLUSÃO}

Declaramos no início que além de fornecermos uma interpretação da psicologia dos vícios diabólicos de Kant, estamos interessados em que medida este grupo de vícios é psicologicamente unificado. Esta questão de unificação se divide em duas perguntas. Primeiro, se, e em que medida, episódios particulares (em um nível geral de descrição) possuem um perfil psicológico igual ou similar. Aqui estão nossas respostas um tanto hesitantes a estas perguntas. Kant diz que estes três vícios surgem de nossa tendência natural a nos contrapormos à superioridade alheia. Novamente, episódios de inveja e ingratidão, argumentamos, compartilham do mesmo padrão psicológico, um padrão que também é evidente ao menos em casos típicos de Schadenfreude. Além disso, há um ingrediente comum em todas manifestações verdadeiramente diabólicas destes vícios, a saber, o elemento do ódio direcionado aos outros, o qual é contrário, e não meramente indiferente, ao fim universal obrigatório de promover o bem-estar dos outros.

\section{REFERÊNCIAS}


ADAMS, R. M. A Theory of Virtue: Excellence in Being for the Good. Oxford: Oxford University Press, 2006

ARISTOTLE. Rhetoric. W. Rhys Roberts, trans. In R. McKeon, ed., The Basic Works of Aristotle. New York: Random House, 1941.

BELTZER, M. Kant's Theory of Virtue. Berlin: Walter de Gruyter, 2008

GREGOR, M. Practical Philosophy. Cambridge: Cambridge University Press, 1996

HEATH, P. and J. B. SCHNEEWIND. Lectures on Etbics. P. Heath, trans., Cambridge: Cambridge University Press, 1997.

ROBERTS, R. C. "Will Power and the Virtues." Philosophical Review 93, 1984, $227-47$.

SMIT, H. \& M. TIMMONS. "The Moral Significance of Gratitude in Kant's Ethics." Southern Journal of Philosophy 49, 2011, pp. 295-320,.

TIMMONS, M. "The Perfect Duty to Oneself as an Animal Being." in A. Tampota, O. Sensen, and J. Timmermann, eds., Kant's Tugendlehre. Berlin \& New York: de Gruyter, 2013, pp. 221-243.

ZÖLLER, G. \& R. LOUDEN. Anthropology, History, and Education. Cambridge: Cambridge University Press. (Translations of Anthropology and Pedagogy, by R. Louden.) 2007. 